
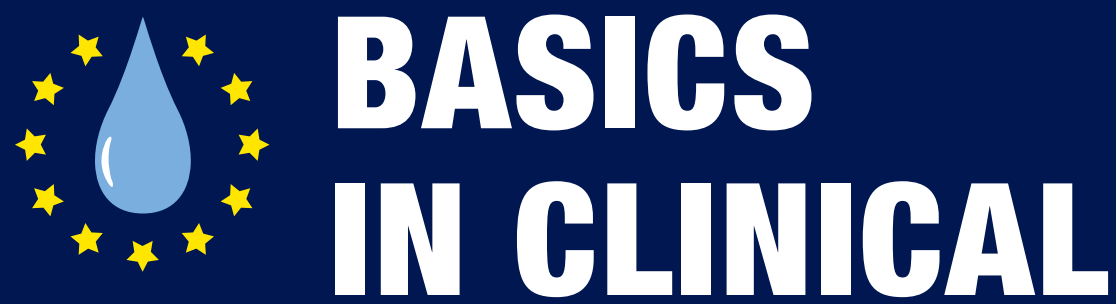

NUTRITION

\title{
Fifth Edition
}

Editor in Chief

Luboš Sobotka

Associate Editors

Simon P. Allison

Alastair Forbes

Rémy F. Meier

Stéphane M. Schneider

Peter B. Soeters

Zeno Stanga

Andre Van Gossum 


\section{BASICS \\ IN CLINICAL \\ NUTRITION \\ Fifth Edition}

Editor in Chief

Luboš Sobotka

Associate Editors

Simon P. Allison

Alastair Forbes

Rémy F. Meier

Stéphane M. Schneider

Peter B. Soeters

Zeno Stanga

Andre Van Gossum 


\section{BASICS IN CLINICAL NUTRITION}

\section{Fifth edition}

\section{Editor in Chief Luboš Sobotka}

Publishing House Galén

Na Popelce 3144/10a, 15000 Prague 5, Czech Republic

Managing Editor Lubomír Houdek, Dr.

Editor-in-Chief Soňa Dernerová, Dr.

Composition Václav Zukal - Galén, Prague

Print FINIDR, s. r. o., Lipová 1965, 73701 Český Těšín, Czech Republic

www.espenbluebook.org

All rights reserved. This book, or any thereof, may not be used or reproduced in any manner without written permision. For information, address European Society of Parenteral and Enteral Nutrition.

Supported by the program PROGRES Q40/12.

(C) ESPEN, 1999, 2000, 2004, 2011, 2019

(c) Galén, 1999, 2000, 2004, 2011, 2019 


\section{Editor in Chief}

Luboš Sobotka, MD, PhD

Professor of Medicine

$3^{\text {rd }}$ Department of Medicine

Metabolic Care and Gerontology

Medical Faculty - Charles University

Hradec Králové

Czech Republic

\section{Associate Editors}

Simon P. Allison, MD, FRCP

Professor in Clinical Nutrition

Department of Diabetes, Endocrinology

and Nutrition

Queen's Medical Center

Nottingham

United Kingdom

Alastair Forbes, BSc, MD, FRCP, FHEA

Clinical Professor of Medicine

Chief of Research and Innovation

Norwich Medical School

University of East Anglia

Norwich

United Kingdom

\section{Rémy F. Meier, MD}

Professor of Medicine

Head of Department of Gastroenterology,

Hepatology and Nutrition

University Hospital

Kantonsspital Liestal

Liestal

Switzerland

Stéphane M. Schneider, MD, PhD, FEBGH

Professor of Nutrition

Nutritional Support Unit

Archet University Hospital

Nice

France

\section{Peter B. Soeters, MD, PhD}

Emeritus Professor of Surgery

Department of Surgery

University Hospital Maastricht

Maastricht

The Netherlands

\section{Zeno Stanga, MD, PhD}

Professor in Internal Medicine and Clinical

Nutrition

Division of Endocrinology, Diabetes and

Clinical Nutrition

Division of General Internal Medicine

University Hospital

Bern

Switzerland

\section{Andre Van Gossum, MD, PhD}

Professsor

Head of the Clinic of Intestinal Diseases

and Nutritional Support

Department of Gastroenterology

Hopital Erasme

Universite Libre de Bruxelles

Brussels

Belgium 


\section{List of authors}

Michael Adolph, MD, PhD

Associate Professor

Head of Nutrition Support Team

Senior Physician Anesthesiology and Intensive

Care Medicine

University Clinic Tuebingen

Tuebingen

Germany

\section{Carla Aeberhard, $\mathrm{PhD}$}

Department of Endocrinology, Diabetes and

Clinical Nutrition

Bern University

Hospital and University of Bern

Bern

Switzerland

\section{Simon P. Allison, MD, FRCP}

Professor in Clinical Nutrition

Department of Diabetes, Endocrinology and

Nutrition

Queen's Medical Center

Nottingham, UK

\section{Raffaella Antonione, MD}

Internal Medicine

Clinica Medica, Ospedale di Cattinara

Azienda Ospedaliero-Universitaria

Trieste

Italy

\section{Peter Austin}

Senior Pharmacist

Southampton University NHS Hospitals Trust

Southampton

United Kingdom

\section{Mette M Berger, MD, PhD}

Professor of Intensive care medicine

Service of Intensive Care Medicine \& Burns

Lausanne University Hospital (CHUV)

$\mathrm{CH}$ - 1011 Lausanne

Switzerland
Stephan C Bischoff, MD, PhD

Professor of Medicine

Institute of Nutritional Medicine

University of Hohenheim

Stuttgart

Germany

Gyorgy Bodoky, MD, PhD

Professor of Oncology

St. Laszlo Teaching Hospital

Department of Oncology

Budapest

Hungary

Prof Yves Boirie, MD, PhD

University of Clermont-Ferrand

Clinical Nutrition department of the University

Hospital of Clement-Ferrand

Human Nutrition Research Center

Clermont-Ferrand

France

Marian A. E. van Bokhorst - de van der

Schueren, RD, PhD

Senior nutrition scientist

Department of nutrition and dietetics

VU University Medical Center

Amsterdam

The Netherlands

Dr Kurt Boeykens

Clinical Nutrition Nurse Specialist

Nutrition Support Team

AZ Nicolaas Hospital

Sint-Niklaas

Belgium

Federico Bozzetti, MD

Surgeon oncologist

Faculty of Medicine

University of Milan

Milan

Italy 
Valentina Bozzetti, MD, PhD

Neonatal Intensive Unit

San Gerardo Hospital

Monza

Italy

\section{Marco Braga, MD}

Professor of Surgery

San Raffaele University

Milan

Italy

\section{Fang Cai, MD}

Physician

Unit of Nutrition

Geneva University Hospital

1211 Geneva 14

Switzerland

\section{Philip C. Calder, PhD, DPhil}

Professor of Nutritional Immunology

Institute of Human Nutrition and Human

Development and Health Academic Unit

Faculty of Medicine

University of Southampton

Southampton General Hospital

Southampton

United Kingdom

\section{Maria E. Camilo, $\mathrm{MD}, \mathrm{PhD}$}

Professor of Medicine and Nutrition

Research Unit of Nutrition and Metabolism

Institute of Molecular Medicine

Medical Faculty

Lisbon University

Lisbon

Portugal

\section{Noël Cano, $\mathrm{MD}, \mathrm{PhD}$}

Professor of Nutrition

Human Nutrition Research Center of Auvergne

Human Nutrition Unit, UMR 1019 INRA-

Clermont University

Clinical Nutrition Unit, Clermont-Ferrand

University Hospital

Clement-Ferrand

France
Anja Carlsohn, Prof, Dr

Department of Ecotrophology

Faculty of Life Science

University of Applied Science

Hamburg

Germany

\section{Yvon A. Carpentier, MD}

Professor of Pathological Biochemistry and Nutrition

L. Deloyers Laboratory for Experimental

Surgery

Université Libre de Bruxelles

Brussels

Belgium

\section{Tommy Cederholm, MD, PhD}

Professor of Clinical Nutrition

Department of Public Health and Caring

Sciences

Uppsala University

Uppsala

Sweden

\section{Emanuele Cereda, MD, PhD}

Researcher and Physician

Nutrition and Dietetics Service

IRCCS Fondazione Policlinico San Matteo

Pavia

Italy

Irit Chermesh, MD

Deputy Director of Gastroenterology

Department

Medical Director of Clinical Nutrition

Rambam Health Care Campus

Haifa

Israel

Michael Chourdakis, MD, RD, MPH, PhD

Assistant Professor of Medical Nutrition

Dept.of Medicine

Aristotle University of Thessaloniki

Thessaloniki

Greece 
Luc Cynober, PharmD, PhD

Professor of Nutrition

Head of Departments

Dept. of Experimental, Metabolic and Clinical

Biology

Pharmacy Faculty - Paris Descartes University and Clinical Chemistry Department

Cochin and Hôtel-Dieu Hospitals, APHP

Paris

France

Erno Dardai, MD, PhD

Department of Anesthesiology and Intensive

Therapy

St. Stephen's Hospital

Budapest

Hungary

Sarah Delliere, MD, MS

Service de Biochimie

Hopital Cochin

Groupe Hospitalier HUPC, APHP

Paris

France

Nicolaas E. P. Deutz, MD, PhD

Professor of Geriatrics. Professor of Pediatrics and Nutrition

Center for Translational Research in Aging

\& Longevity

Department of Health and Kinesiology

Texas A\&M University

College Station, TX

USA

\section{David F. Driscoll, PhD}

Vice President

Stable Solutions LLC

Easton, MA

USA
Wilfred Druml, MD

Professor of Medicine

Medical Department III

Division of Nephrology

University of Vienna and Vienna

General Hospital

Vienna

Austria

\section{Stanley J. Dudrick, MD, FACS}

Professor of Surgery

Chairman, Department of Surgery

Director, Program in Surgery

St. Mary's Hospital

Waterbury, CT

Yale University School of Medicine

New Haven, CT

USA

\section{Marinos Elia, MD, FRCP}

Professor of Clinical Nutrition \& Metabolism

Institute of Human Nutrition

University of Southampton

Southampton General Hospital

Southampton

United Kingdom

Nicholas D. Embleton, MD, MBBS, FRCPCH,

BSc

Consultant Neonatal Pediatrician

Honorary Reader in Neonatal Medicine

Royal Victoria Infirmary

Newcastle Hospital

NHS Foundation Trust

Newcastle upon Tyne

United Kingdom

Joel Faintuch, MD, PhD

Senior Professor

Department of Gastroenterology

Sao Paulo University Medical School

Sao Paulo

Brazil 
Joel J. Faintuch, MD, PhD

Professor of Medicine

Department of Medicine

Hospital das Clinicas

Sao Paulo University Medical School

Sao Paulo

Brazil

\section{Enrico Fiaccadori, MD, PhD}

Renal Failure Unit

Division of Nephrology

Parma University Hospital

University of Parma

Parma

Italy

Eric Fontaine, MD, PhD

Professor of Medicine

INSERM U1055 - LBFA

Joseph Fourier University

Grenoble Cedex

France

Alastair Forbes, BSc, MD, FRCP, FHEA

Clinical Professor of Medicine

Chief of Research and Innovation

Norwich Medical School

University of East Anglia

Norwich

United Kingdom

Konstantinos C. Fragkos, MB, BS, MSc, PhD Clinical Research Fellow in Gastroenterology and Clinical Nutrition

University College London

London

United Kingdom

Wim G. van Gemert, MD, PhD

Colorectal, Gastrointestinal and Pediatric

Surgeon

Academic Hospital Maastricht and Maastricht

University

Maastricht

The Netherlands
Laurence Genton, MD, PhD

Professor in Clinical Nutrition

Clinical Nutrition

Geneva University Hospital

Geneva

Switzerland

\section{Cristina Gonzalez, MD, PhD}

Professor of Post-Graduation Program in Health and Behaviour

Catholic University of Pelotas

Pelotas RS

Brazil

\section{Olivier Goulet, MD, PhD}

Professor of Paediatrics

Department of Gastroenterology

Hopital Necker Enfans-Malades

Paris

France

Robert F. Grimble, BSc, PhD, RNutr

Professor of Nutrition

Division of Developmental Origins

of Health and Disease

School of Medicine

University of Southampton

Southampton

United Kingdom

Martin Haluzík, MD, PhD

Professor of Medicine

Department of Experimental Diabetology

Institute for Clinical and Experimental Medicine

Prague

Czech Republic

Folke Hammarqvist, $\mathrm{MD}, \mathrm{PhD}$

Professor in Emergency Surgery

Department of Surgical Gastrocenter.

CLINTEC - Department of Clinical Science, Intervention and Technology

Karolinska University Hospital Huddinge

Stockholm

Sweden 
Gil Hardy, PhD, FRSC

Professor of Pharmaceutical Nutrition

Faculty of Medical and Health Sciences

University of Auckland

Auckland

New Zealand

\section{Laszlo Harsanyi, MD, PhD}

Professor of Surgery

1st Surgical Department

Faculty of Medicine

Semmelweis University

Budapest

Hungary

\section{Reem Hawarym RD}

King Faisal Specialist Hospital \& Research

Center

11578 Riyadh

Saudi Arabia

\section{J Pat Howard, RD}

Head of Nutrition and Dietetic Services

United Bristol Healthcare Trust

Bristol Royal Infirmary

Bristol BS2 8HW

United Kingdom

Pao Ying Hsiao, MS, RD, LDN

Assistant Professor and Registered Dietitian

Department of Nutritional Sciences

Pennsylvania State University

USA

Martin Hubner, MD, PD

Consultant Surgeon

Department of Visceral Surgery

Lausanne University Hospital - CHUV

Lausanne

Switzerland

\section{Gordon L Jensen, MD, PhD}

Professor of Medicine

Head of Department of Nutritional Sciences

Pennsylvania State University

USA
Philippe Jolliet, MD

Senior Lecturer

Medical Intensive Care

Geneva University Hospital

Geneva

Switzerland

Cora F. Jonkers-Schuitema, RD, Bc

Dietitian

Academic Medical Center

Amsterdam

The Netherlands

Francisco J. Karkow, MD, PhD

Full Professor

Department of Nutrition

Fatima Faculty

Caxias do Sul

Brazil

\section{Luiza Kent-Smith, PhD, RD}

Professional Leader Nutrition \& Dietetics

Saskatoon Health Region

Saskatoon

Canada

\section{Berthold Koletzko, MD, PhD}

Professor of Paediatric

Division Metabolic and Nutritional Medicine

Dr. von Hauner Children's Hospital

Ludwig-Maximilians-University of Munich

Munich

Germany

Jens Kondrup, MD, Dr Med Sci

Professor in Clinical Nutrition

Clinical Nutrition Unit 5711

Rigshospitalet University Hospital,

Copenhagen

Denmark

\section{Angela Koverech, MD}

Department of Clinical and Molecular Medicine

Sapienza University

Rome

Italy 


\section{Zeljko Krznarič, MD, PhD, FEBGH}

Professor of Medicine

Head of Division of Gastroenterology

Department of Medicine

University of Zagreb

Zagreb

Croatia

\section{Irma Kushta, MD}

Department of Clinical Medicine

Sapienza - University of Rome

Rome

Italy

\section{Alexey V. Lapitsky, MD, PhD}

Research scientist

Laboratory of Clinical Nutrition

Saint-Petersburg I.I. Dzhanelidze Research

Institute of Emergency Medicine

Saint-Petersburg

Russian Federation

Miguel Leon-Sanz, MD, PhD

Professor Endocrinology and Nutrition

Department of Medicine

Medical School

University Hospital Doce de Octubre

Complutense University

Madrid

Spain

Olle Ljungqvist, $\mathrm{MD}, \mathrm{PhD}$

Professor of Surgery

Faculty of Medicine and Health,

School of Health and Medical Sciences

Department of Surgery

Örebro University,

Örebro

Sweden

\section{Valery M. Luft, MD, PhD}

Professor, Head of Laboratory of Clinical

Nutrition

Saint-Petersburg I.I. Dzhanelidze Research Institute of Emergency Medicine

Saint-Petersburg

Russian Federation
Stanislav Klek, MD, PhD

Professor of Surgery

General and Oncology Surgery Unit

Stanley Dudrick's Memorial Hospital

Skawina

Poland

\section{Marek Kunecki, MD}

Specialist in General Surgery

Department of Clinical Nutrition

Department of General and Vascular Surgery

M. Pirogow Provincial Specialist Hospital

Lodz

Poland

\author{
Alessandro Laviano, MD \\ Associate Professor of Medicine \\ Department of Translational and Precision \\ Medicine \\ Sapienza University of Rome \\ Rome \\ Italy
}

Dileep N Lobo, MS, DM, FRCS, FACS

Professor of Gastrointestinal Surgery

Nottingham University Hospitals

Queen's Medical Centre

Nottingham NG7 2UH

United Kingdom

Jan Maňák, $\mathrm{MD}, \mathrm{PhD}$

3rd Department of Medicine

Metabolic Care and Gerontology

Medical Faculty - Charles University

Hradec Králové

Czech Republic

Luis Matos, MSc

Department of Nutrition

USL Gurda

Porto

Portugal 
Michael M. Meguid, MD, PhD

Professor Emeritus

Surgery, Neuroscience and Physiology

Department of Surgery

Upstate Medical University

University Hospital

Syracuse, NY

USA

\section{Rémy F. Meier, MD}

Professor of Medicine

Head of Department of Gastroenterology,

Hepatology and Nutrition

University Hospital

Kantonsspital Liestal

Liestal

Switzerland

\section{Katarina Melzer, PhD}

Equiliberty Consulting, LLC

University of Lausanne

Lausanne

Switzerland

Maarten F. von Meyenfeldt, MD, PhD

Professor of Surgical Oncology

Department of Surgery

University Hospital Maastricht

Maastricht

The Netherlands

Alvaro A. C. Morais, MD, MS

Full Professor

Department of Surgery

EMESCAM Medical Scholl

Vitoria

Brazil

\section{Adéla Mrózková, MD}

Department of Hygiene and

Preventive Medicine

Medical Faculty

Charles University

Hradec Králové

Czech Republic

\section{Stefan Mühlebach, $\mathrm{PhD}$}

Professor of Pharmacology and Hospital

Pharmacy

Hospital Pharmacist FPH

Medical Faculty

Division of Clinical Pharmacology \& Toxicology

University Hospital of Basel

Basel

Switzerland

\section{Maurizio Muscaritoli, MD, FACN}

Profesor of Medicine

Department of Clinical Medicine

Sapienza - University of Rome

Rome

Italy

\section{Ton Naber, MD, PhD}

Professor of Clinical Nutrition

Department of Gastroenterology and

Hepatology

Medical Faculty

University Medical Center Nijmegen

Nijmegen

The Netherlands

Luis Alberto Nin, MD

Professor in Nutrition and Director Magister in

Nutrition

Catholic University

Montevideo

Uruguay

\section{Kristina Norman, PhD}

Professor of Nutrition and Gerontology

Department of Nutrition and Gerontology

German Institute for Human Nutrition Potsdam

Rehbrücke

University of Potsdam

Potsdam

Germany 
Ibolya Nyulasi, MSc

Department of Medicine

Alfred Hospital

Faculty of Medicine

Nursing and Health Sciences

Clayton

Australia

\section{Johann Ockenga, MD, PhD}

Professor in Internal Medicine

Department of Gastroenterology,

Endocrinology and Clinical Nutrition

Klinikum Bremen Mitte

Bremen

Germany

\section{Ann Ödlund Olin, PhD, RN}

Manager of nursing development

Department of Quality and Patient Safety

Karolinska University Hospital

Stockholm

Sweden

\section{Olivier Pantet, MD}

Service of Intensive Care Medicine \& Burns

Lausanne University Hospital (CHUV)

$\mathrm{CH}-1011$ Lausanne

Switzerland

\section{Claude Pichard, MD, PhD}

Professor of Medicine

Head of the Unit of Unit of Nutrition

Geneva University Hospital

1211 Geneva 14

Switzerland

\section{Matthias Pirlich, MD, PhD}

Professor of Medicine

Head of Department

Department of Internal Medicine

Evangelische Elisabeth Klinik

Lützowstr. 24-26

10785 Berlin

Germany

\section{Loris Pironi, MD}

Associate professor of Food and Dietetic

Sciences

Department of Medical and Surgical Science

School of Medicine

University of Bologna

Bologna

Italy

Mathias Plauth, MD

Professor of Medicine

Head of Department of Internal Medicine

Community Hospital Dessau

Dessau

Germany

Jean-Charles Preiser, MD, PhD

Clinical Director

Department of Intensive Care

Erasme University Hospital

Brussels

Belgium

John W. L. Puntis, BM (Hons), DM, FRCP, FRCPCH

Consultant Paediatric Gastroenterologist

The General Infirmary at Leeds

Leeds, West Yorkshire

United Kingdom

Petronella Lucia Martha Reijven, MSc, PhD

Nutritional Scientist

Department of Clinical Dietetics

Maastricht University Medical Centre

Maastricht,

The Netherlands

Filippo Rossi Fanelli MD, FACN

Profesor of Medicine

Department of Clinical Medicíně

Sapienza - University of Rome

Rome

Italy 


\section{Nada Rotovnik Kozjek, MD, PhD}

Associate Professor of Oncology and Dietetics Institute of Oncology

Clinical Nutrition Unit

Medical Faculty

University of Ljubljana

Slovenia

\section{Hans P. Sauerwein, MD}

Emeritus Professor of Energy Metabolism

Academic Medical Center

Amsterdam

The Netherlands

\section{Anastasia M. Sergeeva, MD}

Junior research scientist

Laboratory of Clinical Nutrition

Saint-Petersburg I. I. Dzhanelidze Research Institute of Emergency Medicine

Saint-Petersburg

Russian Federation

Alan Shenkin, PhD, BSc, FRCP, FRCPath

Emeritus Professor

School of Clinical Sciences

University of Liverpool

Liverpool

L69 3GA

United Kingdom

Stéphane M. Schneider, MD, PhD, FEBGH

Professor of Nutrition

Nutritional Support Unit

Archet University Hospital

Nice

France

Jos M. G. A. Schols, MD, PhD

Professor of chronic care and nursing home medicine

Department of General Practice

Maastricht University

Maastricht

The Netherlands
Philipp Shütz, MD, MPH

Professor of Medicine

Medical University Department

Kantonsspital Aarau

Aarau

Switzerland

\section{Pierre Singer, MD}

Clinical Professor in Anaesthesia and Intensive

Care

Department of General Intensive Care and institute for Nutrition Research

Tel Aviv University

Rabin Medical Center, Beilinson Hospital

Petah Tikva

Israel

\section{Antonio Sitges-Serra, MD, FRCS}

Professor of Surgery

Head of Department of Surgery

University Hospital del Mar

Barcelona University

Barcelona

Spain

Jacek Sobocki, MD, PhD

Professor of Surgery

Department of Surgery and Clinical Nutrition

Medical University of Warsaw

Warsaw

Poland

\section{Luboš Sobotka, $\mathrm{MD}, \mathrm{PhD}$}

Professor of Medicine

$3^{\text {rd }}$ Department of Medicine

Metabolic Care and Gerontology

Medical Faculty - Charles University

Hradec Králové

Czech Republic

\section{Ondřej Sobotka, MD, $\mathrm{PhD}$}

$3^{\text {rd }}$ Department of Medicine

Metabolic Care and Gerontology

Medical Faculty - Charles University

Hradec Králové

Czech Republic 
Maarten R. Soeters, MD, PhD

Department of Endocrinology and Metabolism

University of Amsterdam

Academic Medical Center

Amsterdam

The Netherlands

P. B. Soeters, $\mathrm{MD}, \mathrm{PhD}$

Emeritus Professor of Surgery

Department of Surgery

University Hospital Maastricht

Maastricht

The Netherlands

Mattias Soop, MD, PhD

Consultant surgeon

Irving National Intestinal Failure Unit

Salford Royal Hospital

Reader Manchester University

United Kingdom

Zeno Stanga, MD, PhD

Professor in Internal Medicine and Clinical

Nutrition

Division of Endocrinology, Diabetes and

Clinical Nutrition

Division of General Internal Medicine

University Hospital

Bern

Switzerland

Rebecca Stratton, PhD, RD, RNutr

Institute of Human Nutrition

University of Southampton

Southampton General Hospital

Southampton

United Kingdom

Štěpán Svačina, $\mathrm{MD}, \mathrm{PhD}$

Professor of Medicine

Head of the $3^{\text {rd }}$ Department of Internal Medicine

Medical Faculty 1

Charles University

Prague

Czech Republic
Bruno Szczygiel, MD, PhD

Professor of Surgery

Department of Human Nutrition

Medical University of Warsaw

Warsaw

Poland

\section{Luc Tappy, MD}

Professor of Physiology

Chairman, Department of Physiology

School of Biology and Medicine

Lausanne University

Lausanne

Switzerland

Vladimír Teplan, MD, PhD

Profesor of Medicine

Institute for Postgraduál Education

Department of Nephrology

Institute for Clinical and Experimental Medicíne

Prague

Czech Republic

\section{Ronan Thibault, $\mathrm{MD}, \mathrm{PhD}$}

Professor of Nutrition

NuMeCan Institute

CHU Rennes, Univ. Rennes, INSERM, INRA

Dept. Nutrition and Endocrinology

Referral Centre for Rare Digestive Diseases

Home Parenteral Nutrition Centre

Rennes

France

\section{Christel Tran, MD}

Consulting Physician

Division of Endocrinology Diabetes and

Metabolism

Lausanne University Hospital

Lausanne

Switzerland

Elena Y. Tyavokina, MD

Head of Somatopsychiatry Department

Saint-Petersburg I.I. Dzhanelidze Research

Institute of Emergency Medicine

Saint-Petersburg

Russian Federation 
Nachum Vaisman, MD

Professor of Pediatrics

Head of Clinical Nutrition Unit

Tel Aviv Sourasky Medical Center

and Tel Aviv Sourasky Medical School

Tel Aviv

Israel

Maurits F. J. Vandewoude, MD, PhD

Professor of Medicine

Department of Geriatrics

Faculty of Medicine

University of Antwerp

Antwerp

Belgium

\section{Andre Van Gossum, MD, PhD}

Professsor

Head of the Clinic of Intestinal Diseases and

Nutritional Support

Department of Gastroenterology

Hopital Erasme

Universite Libre de Bruxelles

Brussels

Belgium

Geert Wanten, MD, PhD, MSc

Gastroenterologist, Head Nutrition Support

Team

Intestinal failure Unit

Department of Gastroenterology and

Hepatology

Radboud University Nijmegen Medical Centre

Nijmegen

Nijmegen

The Netherlands
Jan Wernerman, MD, PhD

Professor in Anaesthesia

Department of Anaesthesia and Intensive Care

CLINTEC - Department of Clinical Science,

Intervention and Technology

Karolinska University Hospital Huddinge

Stockholm

Sweden

\section{Klaas R Westerterp, PhD}

Professor of Human Energetics

Department of Human Biology

Maastricht University

Maastricht

The Netherlands

\section{Thomas Wild, MD}

Departments of Dermatology, Venereology,

Allergology and Immunology

Dessau Medical Center

Dessau

Germany

\section{Zdeněk Zadák, MD, PhD}

Professor of Medicine

$3^{\text {rd }}$ Department of Medicine, Metabolic Care and Gerontology

Medical Faculty - Charles University

Hradec Králové

Czech Republic 


\section{CONTENTS}

\section{BASIC CONCEPTS}

IN NUTRITION $\ldots \ldots \ldots \ldots \ldots \ldots, 1$

1.1. Energy and protein balance. ....... 1

1.2. Body composition ............ 6

1.2.1. Measurement of body composition ... 6

1.2.1.1. Background . . . . . . . . . . . . . 6

1.2.1.2. Densitometry. ............... 7

1.2.1.3. Hydrometry . . . . . . . . . . . . . 7

1.2.1.4. Anthropometry.............. 8

1.2.1.5. Electrical conductance............ 9

1.2.1.6. Body imaging $\ldots \ldots \ldots \ldots \ldots \ldots 10$

1.2.1.7. Discussion .................. 10

1.2.2. Bioelectrical Impedance Analysis. . . . 12

1.2.2.1. Basic principle of the method ....... 12

1.2.2.2. Factors which influence BIA measurement............... 14

1.2.2.3. BIA as marker of tissue health . . . . 15

1.2.2.4. BIA methods used in clinical practice................... 16

1.3. Diagnosis of malnutrition Screening and Assessment. ....... 18

1.3.1. Definition of Malnutrition. ......... 18

1.3.1.1 Malnutrition - Undernutrition........ 18

1.3.1.2. Interaction between undernutrition and inflammation ............. 18

1.3.1.3. Malnutrition - Overnutrition....... 19

1.3.2. Screening for malnutrition ........ 20

1.3.3. Nutritional Assessment .......... 20

1.3.4. Techniques used in nutritional assessment ................. 23

1.3.4.1. Anthropometry............... 23

1.3.4.2. Advanced measures of function ..... 24

1.3.4.3. Laboratory Tests . . . . . . . . . . . . 24

1.4. The influence of malnutrition on

function . . . . . . . . . . . . . 27

1.4.1. Cognitive function . . . . . . . . . . 28

1.4.2. Muscle function ................ 28

1.4.3. Cardiovascular function ......... 28
1.4.4. Renal function. .............. 28

1.4.5. Respiratory function $\ldots \ldots \ldots \ldots . \ldots 29$

1.4.6. Gastrointestinal tract ............ 29

1.4.7. Thermoregulation............... 29

1.4.8. Immune system. .............. 29

1.4.9. Wound healing $\ldots \ldots \ldots \ldots \ldots \ldots 30$

1.4.10. Quality of life............... 30

1.5. Overnutrition - functional and clinical consequences ........... 31

1.5.1. Physiology of adipose tissue . ...... 31

1.5.2. Acute overfeeding.............. 33

1.5.3. Chronic overfeeding - Obesity...... 33

1.5.3.1. Aetiology of obesity ........... 33

1.5.3.2. Classification of obesity.......... 35

1.5.3.3. Obesity and metabolic complications ................ 35

1.5.3.4. Metabolic syndrome . .......... 36

1.5.4. Treatment of obesity ............ 36

1.6. Prevalence of malnutrition . . . . . . 39

1.6.1. Malnutrition ................... 39

1.6.2. Identifying malnutrition ......... 40

1.6.3. Prevalence of malnutrition ........ 41

1.6.3.1. Underweight and BMI in different countries and world regions ....... 41

1.6.3.2. Prevalence of Malnutrition in a European Country (United Kingdom (UK)) ............... 43

1.6.3.3. Geographic location (geographic inequalities) ................ 45

1.6.3.4. Distribution of malnutrition according to individual characteristics .......46 46

1.6.4. Causes of malnutrition (undernutrition) and evidence for treatment .......46

1.7. Nutritional requirements for health at rest and upon exercise . . . . . . 48

1.7.1. Adult subjects . . . ............ 48

1.7.1.1. Macronutrients ............... 48

1.7.1.2. Micronutrients ............. 53 
1.7.2. Nutritional needs of infants, children and adolescents.............. 55

1.7.2.1. Nutrient requirements for growth and development. .............. 55

1.7.2.2. Nutrient requirements $\ldots \ldots \ldots \ldots 57$

\section{NUTRITIONAL PHYSIOLOGY} AND BIOCHEMISTRY ..........6 69

2.1. Appetite and its control ......... 69

2.1.1. Peripheral signals . . . . . . . . . . 70

2.1.2. Homeostatic control of feeding . . ... 71

2.1.3. Hedonic control of feeding . . . . . . . . 73

2.1.4. Loss of appetite during disease..... 73

2.1.5. Summary ............... 73

2.2. Digestion and absorption of nutrients . . . . . . . . . . . 74

2.2.1. Principal sites of digestion and absorption ............... 75

2.2.2. The small intestine ............ 76

2.2.2.1. Carbohydrates................. 76

2.2.2.2. Lipids . . . . . . . . . . . . . 78

2.2.2.3. Proteins .................... 80

2.2.2.4. Vitamins ................. 82

2.2.2.5. Water, electrolytes, and trace elements .................... 82

2.2.3. The absorptive functions of the colon ................. 83

2.2.3.1. Water and electrolytes .......... 83

2.2.3.2. Metabolic and digestive functions ... 83

2.3. Energy metabolism ............ 85

2.3.1. Calorimetry for the measurement of energy expenditure............ 85

2.3.2. Components of energy expenditure, measurement, and determinants . . . 87

2.3.3. Disease-related alterations in energy expenditure ................. 88

2.4. Carbohydrate metabolism........ 90

2.4.1. Carbohydrates in normal metabolism ................. 90

2.4.2. Regulation of glucose metabolism .... 91

2.4.3. Effects of stress on glucose metabolism .................. 92

2.4.4. Metabolic responses to critical illness ......................... 94

2.5. Lipid metabolism .............. 95

2.5.1. Basic pathways in lipid metabolism . . 95

2.5.2. Lipid metabolism in fasting conditions ................ 98
2.5.3. Influence of surgical stress, sepsis, and organ failure.............. 99

2.6. Protein and amino acid metabolism . . . . . . . . . . . . . . . . . 101

2.6.1. Physiology .................. 101

2.6.2. Protein turnover .............. 102

2.6.3. Metabolism of amino acids ........ 104

2.6.4. Whole body protein synthesis and/or breakdown ..................... 104

2.6.5. Methods for measuring protein metabolism ................. 108

2.7. Water and electrolytes in health and disease . . . . . . . . . . . . . 112

2.7.1. Water and fluid compartments..... 112

2.7.2. Flux of fluid through the gastrointestinal tract. . . . . . . . . . 114

2.7.3. Role of the kidney.............. 114

2.7.4. External fluid balance. ........... 116

2.7.5. Effects of starvation and injury..... 116

2.7.6. Electrolytes ................. 117

2.8. Physiological functions and deficiency states of trace elements and vitamins . . . . . . . . . . . . . 123

2.8.1. Trace elements................. 123

2.8.1.1. Zinc.................... 123

2.8.1.2. Copper ................... 123

2.8.1.3. Iron ....................... 124

2.8.1.4. Selenium ..................... 124

2.8.1.5. Chromium ................. 125

2.8.1.6. Molybdenum ................. 125

2.8.1.7. Manganese.................. 125

2.8.2. Vitamins .................. 127

2.8.2.1. Thiamine (vitamin $\left.B_{1}\right) \ldots \ldots \ldots \ldots 127$

2.8.2.2. Riboflavin (vitamin $B_{2}$ ) $\ldots \ldots \ldots 127$

2.8.2.3. Niacin (vitamin $B_{3}$ or PP) ........ 127

2.8.2.4. Vitamin $B_{6} \ldots \ldots \ldots \ldots \ldots \ldots \ldots$

2.8.2.5. Folate ..................... 128

2.8.2.6. Vitamin $B_{12} \ldots \ldots \ldots \ldots \ldots \ldots . \ldots 128$

2.8.2.7. Biotin ..................... 129

2.8.2.8. Vitamin C. ................... 129

2.8.2.9. Vitamin A . . . . . . . . . . . . . . . . 129

2.8.2.10. Vitamin D . . . . . . . . . . . . . . 130

2.8.2.11. Vitamin E. . . . . . . . . . . . . . . . 130

2.8.2.12. Vitamin K................. 131

2.8.2.13. Vitamins - Summary of influence of metabolic stress. . . . . . . . . . . 131

2.8.2.14. Assessment of vitamin status in clinical practice............. 131

2.9. Antioxidants in health and disease .133 
2.9.1. Oxidative stress ............... 134

2.9.2. Oxidation in vivo and neutralisation of RNOS ................... 135

2.9.3. Dietary recommendations for antioxidants ................ 136

2.10. Dietary fibre: metabolism and physiological effects ........... 137

2.10.1. Physicochemical properties and metabolism of fibre........... 137

2.10.2. Physiological effects and clinical implications of fibre in the gut ..... 140

2.11. The role of gut bacteria in nutrition and metabolism .............. 146

2.11.1. Recent innovations in gut microbiome research ................. 146

2.11.2. Characteristics and regulation of the intestinal microbiome .......... 147

2.11.3. Physiological functions of the intestinal microbiome ................. 149

2.11.4. The role of the intestinal microbiome in obesity and the metabolic syndrome . . . . . . . . . . . . 151

2.11.5. The role of the intestinal microbiome in malnutrition/undernutrition .... 152

2.12. Simple and stress starvation ..... 155

2.12.1. Energy stores ................ 155

2.12.2. Simple starvation ............. 156

2.12.3. Stress starvation ............. 157

2.12.4. Malnutrition and the response to injury ................... 158

2.13. Injury and sepsis ............. 161

2.13.1. The effects of cytokines during injury and sepsis................. 161

2.13.1.1. Reaction of the immune system ... 162

2.13.1.2. Endocrine changes during the inflammatory response ......... 163

2.13.1.3. The immune response exerts a high metabolic and nutritional cost upon the body.................. 163

2.13.1.4. Adverse effects of cytokines. . ..... 165

2.13.1.5. Antioxidant defenses are depleted by infection and trauma ............ 165

2.13.1.6. Influence of phenotype on the cytokine response. ............ 166

2.13.2. The neuroendocrine response $\ldots \ldots 167$

2.13.2.1. Neural stimuli and the sympathetic nervous system . . . . . . . . . 168

2.13.2.2. Endocrine effects on metabolism ... 169

2.13.2.3. Therapeutic implications .......... 170
2.13.3. Metabolic response to injury, stress, and inflammation ............ 172

2.13.3.1. Stress response: . . ............ 173

2.13.3.2. Metabolic and biochemical response during the flow phase.......... 173

2.13.3.3. Convalescent or anabolic phase .... 176

2.13.3.4. Treatment. . . . . . . . . . . . . . . . . 176

2.14. Metabolic response to hypoxia .... 179

2.14.1. Transient response to anoxia or acute hypoxia.................. 180

2.14.2. Functional adaptation to hypoxia.... 181

2.14.3. Molecular adaptation to hypoxia .... 182

2.14.4. Nutritional consequences of chronic hypoxia................. 183

2.15. Nutritional aspects of chronic inflammatory disease . . . . . . . . 185

2.15.1. Chronic inflammation ........... 186

2.15.2. Characteristic disease processes or conditions . . . . . . . . . . . . . . 187

2.15.3. Interventions . . . . . . . . . . . 188

2.16. Pathophysiological consequences of intestinal failure . . . . . . . . . 191

2.16.1. Definition and classification of intestinal failure . . . . . . . . . 191

2.16.2. The process of digestion and absorption of food ............ 192

2.16.3. Mechanisms of intestinal failure in pathophysiological conditions . . . 194

2.17. Metabolic aspects of neurological disease .................. 198

2.17.1. Denervation atrophy ........... 198

2.17.2. Metabolic consequences of muscle denervation .................. 199

2.17.3. Hormonal and systemic consequences................ 200

2.17.4. Amyotrophic lateral sclerosis (ALS) . 201

\section{INDICATIONS FOR}

NUTRITIONAL SUPPORT ....... 205

3.1. Background ................. 205

3.2. A clinical framework for considering the indications for nutritional support ................... 205

3.3. A practical framework for considering the indications for nutritional support . . . . . . . 207

3.3.1. Identify malnutrition or those at risk of malnutrition .............. 207 
3.3.2. Treat malnutrition or those at risk of malnutrition with the appropriate type of nutritional support ........ 209

3.4. Common indications for nutritional support according to healthcare setting and disease. . . . . . . . . 209

\section{ORGANIZATION AND LEGAL} ASPECTS ..................... 213

4.1. Organization of nutritional care . . 213

4.1.1. Policy, standards, protocols, and

Nutrition Steering Groups (NSGs). . 214

4.1.2. Hospital food and catering ....... 215

4.1.3. Education and training ......... 216

4.1.4. Dieticians .................. 216

4.1.5. Nutritional Support Teams (NSTs). . 216

4.1.6. Purchasing and equipment ....... 218

4.2. Ethical and legal aspects ....... . . 219

4.2.1. Beneficence and Non-maleficence ... 219

4.2.2. Autonomy ................. 221

4.2.3. Special situations. . . . . . . . . . . 222

4.2.4. Justice . . . . . . . . . . . . . . . . . 224

\section{SUBSTRATES USED IN}

PARENTERAL AND ENTERAL

NUTRITION . .................. 229

5.1. Energy .................... 229

5.1.1. Goals of nutritional support ...... 229

5.1.2. Energy intake during nutritional support................ 230

5.1.3. Energy intake and acute disease stage .................... 232

5.2. Carbohydrates ............. 234

5.2.1. Carbohydrate metabolism and nutritional support ........... 234

5.2.2. Carbohydrates used in nutrition support.................. 237

5.2.3. Dosages of carbohydrates in parenteral and enteral nutrition .... 239

5.3. Lipids . . . . . . . . . . . . . . . . 244

5.3.1. Enteral nutrition . . . . . . . . . . . 244

5.3.2. Parenteral nutrition ............ 245

5.3.2.1. Different intravenous lipid emulsions for parenteral nutrition .......... 245

5.3.2.2. Reduction of lipid peroxidation . . . . 247 5.3.2.3. Lipid clearance .............. 247
5.3.2.4. Dosage for intravenous lipid emulsions................. 247

5.3.2.5. Monitoring intravenous lipid emulsions..................... 247

5.4. Proteins and amino acids. . . . . . . 249

5.4.1. Requirements of proteins and amino acids in humans .......... 249

5.4.2. Requirements of protein and essential amino acids in disease . . . . 250

5.4.3. Sources and chemical nature...... 250

5.4.4. Assessment of the biological quality of proteins . . . . . . . . . . 251

5.4.5. Amino acids: the building blocks of protein ................. 251

5.5. Water and electrolytes during nutritional support........... 254

5.5.1. Monitoring. ................ 255

5.5.2. Normal requirements........... 255

5.5.3. Abnormal requirements. ......... 255

5.5.4. Oral rehydration solutions ....... 256

5.5.5. Enteral nutrition .............. 256

5.5.6. Subcutaneous fluids ............ 256

5.5.7. Parenteral fluids ............... 257

5.6. Trace elements and vitamins in parenteral and enteral nutrition ... 258

5.6.1. Micronutrients and trace elements. . . 258

5.6.1.1. Individuals at risk of deficiency . . . 258

5.6.1.2. Clinical deficiency syndromes and subclinical deficiency states.... 259

5.6.1.3. Optimisation of provision of micronutrients .............. 259

5.6.1.4. Legislation from the European Union and enteral nutrition (EN) . . 260

5.6.2. Trace elements in PN and EN ...... 261

5.6.3. Vitamins in EN and PN ......... 263

5.7. Dietary fibre: definition and classification.................. 265

5.7.1. Definition.................... 265

5.7.2. Classifications ............... 266

5.7.3. Fibre and GUT microbiota . . ..... 269

5.8. Special substrates. . . . . . . . 271

5.8.1. Antioxidants and phytochemicals in nutrition ................ 271

5.8.1.1. What is an antioxidant? ........ 271

5.8.1.2. Damage associated with depletion of antioxidants............... 271

5.8.1.3. Who might benefit from antioxidant supplements: biomarkers of oxidative stress .................... 272 
5.8.1.4. Overview of antioxidant strategies. . 272

5.8.1.5. Dietary antioxidants........... 273

5.8.1.6. Some remaining questions related to antioxidant therapy:. . . . . . . 273

5.8.2. Nutrients that influence inflammation and immunity: omega- 3 fatty acids . . 274

5.8.2.1. Omega-3 $(\omega-3)$ fatty acids . . . . . . . 274

5.8.2.2. Dietary sources and typical intakes of $\omega$-3 fatty acids ............ 275

5.8.2.3. Supplementation with long-chain $\omega-3$ fatty acids alters the fatty-acid composition of plasma, cells, and tissues in humans .................. 275

5.8.2.4. Mechanisms of action of long-chain $\omega-3$ fatty acids, with a focus on inflammation and immunity ..... 276

5.8.2.5. Experimental studies with long-chain $\omega-3$ fatty acids . . . . . . . . . 277

5.8.2.6. Fish oil in artificial nutrition support................. 277

5.8.3. Nutrients that influence immunity: experimental and clinical data .... 280

5.8.3.1. Glutamine .................. 280

5.8.3.2. Arginine ................. 282

5.8.3.3. Nucleotides . . . . . . . . . . . . . . 283

5.8.3.4. Polyunsaturated fatty acids (PUFAs) . 284

5.8.3.5. Micronutrients ................ 284

\section{TECHNIQUES OF}

NUTRITIONAL SUPPORT . ..... 287

6.1. Enteral nutrition . . . . . . . . . . . 287

6.1.1. Indications and administration of nutrition ................. 287

6.1.1.1. Indications for enteral nutrition . . . . 287

6.1.1.2. Contraindications to enteral nutrition..................... 287

6.1.1.3. Routes for enteral tube feeding. . . . . 287

6.1.1.4. Choice of feeding solution. ....... 287

6.1.2. Methods of delivering enteral nutrition.................. 289

6.1.2.1. Oral nutritional supplements ..... 289

6.1.2.2. Transnasal access .............. 291

6.1.2.3. Endoscopic access: PEG, PEG-J, and D-PEJ ................ 292

6.1.2.4. Surgical access: gastrostomy, needle catheter jejunostomy . . . . . . . . 298

6.1.2.5. Administration of enteral tube feeds . 300
6.1.2.6. Equipment for delivering enteral nutrition.................... 301

6.1.3. Diets for enteral nutrition ........ 303

6.1.3.1. Homemade enteral (tube) nutrition blenderised tube feeding ......... 303

6.1.3.2. Commercially prepared diets for enteral nutrition .............. 307

6.1.4. Pharmaceutical aspects in enteral feeding and drugs . . . . . . . . 314

6.1.4.1. Basic principles and requirements . . 315

6.1.4.2. General approach to evaluate a drug-nutrient regimen in enteral tube feeding ............................ 315

6.1.4.3. Feeding tube ............... 317

6.1.4.4. Nutrients . . . . . . . . . . . . 318

6.1.4.5. Best practices for co-administration of drugs and enteral tube feeding. . . 318

6.1.5. Complications of Enteral Nutrition . . 319

6.1.5.1. Gastrointestinal complications . . . . 320

6.1.5.2. Mechanical complications........ 321

6.1.5.3. Metabolic complications ........ 322

6.2. Parenteral nutrition ............ 324

6.2.1. Methods of delivering parenteral nutrition................. 324

6.2.1.1. Peripheral parenteral nutrition (PPN) . . . . . . . . . . . . . . . 324

6.2.1.2. Central parenteral nutrition ....... 328

6.2.1.3. Complications associated with central venous catheter insertion and care ................. 336

6.2.2. Different systems for parenteral nutrition (AIO vs. MB) . . . . . . . . 342

6.2.2.1. Multiple bottle system . . . . . . . . . 342

6.2.2.2. All-in-One (AIO) system. . . . . . . . 342

6.2.3. Pharmaceutical aspects of parenteral nutrition support ............ 345

6.2.3.1. How to prepare parenteral nutrition (PN) admixtures, and the role and function of the pharmacist ....... 345

6.2.3.2. Stability and compatibility of parenteral nutrition $(\mathrm{PN})$ admixtures................. 354

6.2.3.3. Drugs and nutritional admixtures . . 362

6.2.4. Metabolic complications of parenteral nutrition ............. 371

6.2.4.1. Clinically relevant acute metabolic complications .............. 371

6.2.4.2. Long-term metabolic complications 


\section{MONITORING OF}

NUTRITIONAL SUPPORT ...... 377

7.1. Clinical monitoring . . . . . . . . . 377

7.1.1. Aims and objectives . . . . . . . . . . . 377

7.1.2. Integrated nutrition ........... 378

7.1.3. Parameters.................... 378

7.2. Laboratory measures of response to nutrition ............... 379

7.2.1. Nitrogen balance. . . . . . . . . . . . 379

7.2.2. Proteins as markers of nutritional status. . . . . . . . . . . . . . . . . . . 380

7.3. Refeeding syndrome .......... 383

7.3.1. Pathophysiological factors. . . . . . . . 384

7.3.2. Clinical manifestations .......... 385

7.3.3. Recommendations for prevention and treatment of RFS in adult patients at risk

\section{NUTRITIONAL SUPPORT IN DIFFERENT CLINICAL SITUATIONS.} 391

\subsection{Nutritional support in severe}

malnutrition ................. 391

8.1.1. Nutritional support. . . . . . . . . . . . 392

8.1.2. Oral nutritional support . . . . . . . . 392

8.1.3. Enteral nutrition . . . . . . . . . . . 393

8.1.4. Parenteral nutrition ............. 393

8.1.5. Monitoring. .................. 393

8.1.6. Rehabilitation ................ 393

8.2. Perioperative nutrition . . . . . . . . 395

8.2.1. Preliminary remarks. . . . . . . . . . 395

8.2.2. Patients at low risk from nutrition-related complications .... 396

8.2.3. Malnourished patients .......... 398

8.2.4. Complicated surgical patients. . . . . 399

8.2.5. Prescription of feed ............. 399

8.2.6. Integration ................ 400

8.2.7. Implementation of evidence and adherence to guidelines ........ 400

\subsection{Nutritional support in critically ill} and septic patients........... 402

8.3.1. Enteral versus parenteral nutrition. . . 403

8.3.2. Energy supply . ............... 404

8.3.3. Glucose and carbohydrates . . . . . . . 404

8.3.4. Lipids ................... 406

8.3.5. Proteins and amino acids ........ 406

8.3.6. Vitamins and trace elements . . . . . 407

\subsection{Nutritional support in} inflammatory bowel disease 410

8.4.1. Effect of inflammatory bowel disease on nutritional status and metabolism .................. . 410

8.4.2. Indications for nutritional support. . . 411

8.4.2.1. Treatment and prevention of malnutrition ................4 411

8.4.2.2. Treatment of active phase ....... 413

8.4.3. Preoperative nutrition ........... 414

8.4.4. Relapse prevention ............. 415

8.4.5. Pharmaconutrition in IBD . . . . . . 415

8.4.6. Symptomatic therapy ............ 415

8.5. Nutrition support in liver disease . 417

8.5.1. Oral diet. . . . . . . . . . . . . 417

8.5.2. Dietary supplements. . . . . . . . 418

8.5.3. Enteral feeding $\ldots \ldots \ldots \ldots \ldots \ldots 418$

8.5.4. Parenteral nutrition ............. 419

8.5.5. Conclusions for diagnosis related nutritional therapy ........... 420

8.6. Nutritional support in renal disease ................... 422

8.6.1. Pathophysiology . ............ 422

8.6.2. Nutritional therapy for patients with renal disease................ 423

8.6.2.1. Non-catabolic patients with stable chronic kidney disease (CKD) . . . . . 423

8.6.2.2. Non-catabolic CKD patients on chronic RRT (with or without malnutrition) ............. 424

8.6.2.3. Patients with AKI and HD/CAPD patients with acute catabolic disease .................... 426

8.6.2.4. Solutions for nutritional support . . . 429

8.6.2.5. Complications and monitoring of nutritional support ........... 430

8.6.3. Nutritional management of renal transplantation (RTX) . ......... 430

8.7. Nutrition in pulmonary and cardiac disease . . . . . . . . . . . . 433

8.7.1. Epidemiology ................ 433

8.7.2. Pathophysiology and consequences of malnutrition .............. 434

8.7.2.1. Pulmonary disease ............ 434

8.7.2.2. Cardiovascular disease. . . . . . . . 436

8.7.3. Nutritional support and intervention............... 437

8.7.3.1. Pulmonary disease ............ 437

8.7.3.2. Cardiovascular disease. ......... 438 


\subsection{Nutritional support in acute and} chronic pancreatitis ........... 441

8.8.1. Acute pancreatitis ........... 441

8.8.1.1. Outcome predictors . . . . . . . . . 442

8.8.1.2. Physiology and pathophysiology with respect to nutrition and fluid resuscitation. .................. 442

8.8.1.3. Treatment of acute pancreatitis . . . . 444

8.8.1.4. Nutritional support. . . . . . . . . . . 445

8.8.2. Chronic pancreatitis............ 449

8.8.2.1. Nutritional treatment in chronic pancreatitis................ 449

8.9. Nutritional support for GI fistulas . 452

8.9.1. Definition and classifications ..... 452

8.9.2. General principles of fistula treatment................. 453

8.9.3. Metabolic care and nutrition....... 454

8.9.4. Nutritional preparation for elective surgery of the persistent fistula..... 457

8.10. Nutritional support in extensive gut resection (short bowel syndrome) . . 459

8.10.1. Aetiology of short bowel syndrome . . 460 8.10.2. Pathophysiology . ............ 460

8.10.3. Complications of SBS . . . . . . . . 461

8.10.4. Small bowel adaptation ........... 463

8.10.5. Management of SBS . . . . . . . . . . 463

8.10.6. Dietary management of SBS . . . . . . 464

8.10.7. The role of the dietician and specialist nurse in SBS treatment .... 468

\subsection{Nutritional support in the} diabetic patient ............. 470

8.11.1. Dietary management of diabetes mellitus................... 471

8.11.2. Nutritional support of the diabetic. . 471 8.11.3. Perioperative management ....... 474

\subsection{Nutritional support in burn} patients ................. 477

8.12.1. Pathophysiology . . . . . . . . . . . 477

8.12.1.1. Fluid loss . . . . . . . . . . . . . . . 477

8.12.1.2. Metabolic response. . . . . . . . . . . 477

8.12.2. Treatment .................. 478

8.12 .2 .1 . Fluid resuscitation .............. 478

8.12.2.2. Energy and substrate requirements . . 479

8.12.2.3. Nutriceuticals in burns. ......... 481

8.12.2.4. Route of nutritional administration. . 482

8.12.2.5. Non-nutritional measures ....... 483

8.12.2.6. Monitoring the response to nutritional therapy ........... 483

\subsection{Nutritional support in cancer} patients .................. 485

8.13.1. General features of the nutritional support................. 486

8.13.2. Nutritional regimen ........... 486

8.13.3. Indications ............... 488

8.13.4. Perioperative nutrition. ......... . 488

8.13.5. Non-surgical cancer patients. . . . . . 490

8.14. Cancer cachexia . . . . . . . . . . . . . . 496

8.14.1. Definition and classification ....... 496

8.14.2. Pathophysiology . .............. 497

8.14.3. Clinical impact of cachexia ....... 501

8.15. Radiation enteropathy . . . . . . . . . 503

8.15.1. Risk factors for RE . . . . . . . . . . . . 504

8.15.2. Clinical approach ............. 504

8.15.3. Role of oral dietetic regimens and parenteral nutrition ........... 505

8.15.4. Nutritional regimen . . . . . . . . . . 506

8.15.5. Outcome. ................... 507

8.16. Nutritional support in AIDS. . . . . . 509

8.16.1. History and pathophysiology . . . . . . 509

8.16.2. Metabolic and nutritional consequences of HIV infection. . . . . 510

8.16.3. Side effects of the drugs . ....... 510

8.16.4. Indications for and aims of nutritional support ........... 511

8.16.5. Dietary counselling. ........... 513

\subsection{Effect of anticachectic agents} in cancer ................. 514

8.17.1. Appetite-stimulating agents . ..... 514

8.17.2. Anticatabolic agents .......... 516

8.17.3. Anabolic agents.............. 517

8.17.4. Other agents .............. 517

8.18. Nutrition and wound healing ..... 519

8.18.1. Phases of wound healing ......... 519

8.18.2. Non-healing chronic wounds ...... 521

8.18.3. Local wound management ........ 522

8.18.4. Nutrition and wound healing ...... 522

8.18.5. Special substrates and wound healing ................... 523

8.19. Nutrition and pressure ulcers . . . 525

8.19.1. Classification and aetiology of pressure ulcers.............. 525

8.19.2. Pathophysiology . .............. 526

8.19.3. Nutritional status and pressure ulcers. . . . . . . . . . . . . . . 526

8.19.4. Nutritional management is relevant to total PU care . . . . . . . . . . 527 
8.19.5. Nutritional intervention and pressure ulcers - what is currently known . . . 527

8.20. Nutritional therapy for neurological disorders ................... 531

8.20.1. Nutritional assessment. . . . . . . . . 531

8.20.2. Nutritional requirements . . . . . . 532

8.20.3. Nutritional support ........... 533

\subsection{Eating disorders - Anorexia}

nervosa. .................. 536

8.21.1. Pathogenesis ................ 537

8.21.2. Physiological changes........... 537

8.21.3. Clinical manifestations and complications ................ 537

8.21.4. Complications ............... 539

8.21.5. Nutritional assessment. . . . . . . . . 539

8.21.6. Nutritional treatment. .......... 539

8.21.7. Long-term effects ............. 540

\subsection{Nutrition support in obese}

patients ................. 542

8.22.1. The obesity paradox ............ 542

8.22.2. Sarcopenic obesity ............ 543

8.22.3. Consequences of obesity in the hospital setting ............. 543

8.22.4. Critical care obese patients ....... 544

8.22.5. Surgical obese patients........... 545

8.22.6. Non-surgical obese patients ....... 545

8.22.7. Calories and Protein: how much?. . . . 546

8.22.8. Micronutrient deficiencies. . . . . . . . 546

8.22.9. Drug avoidance to prevent obesity. . 547

8.23. Nutritional consequences of bariatric and metabolic surgery . ......... 551

8.23.1. Principal bariatric and metabolic modalities. . . . . . . . . . . . . . . . . 551

8.23.2. Perioperative nutritional management ............... 551

8.23.3. Expected weight loss ........... 553

8.23.4. Early nutritional complications .... 554

8.23.5. Long-term nutritional and metabolic complications ................ 555

8.23.6. Priorities in nutritional supplementation ............. 556

8.23.7. Recommendations for pregnancy ... 558

8.23.8. Attention to children and adolescents .............. 558

8.23.9. Refeeding the undernourished bariatric subject. . . . . . . . . . . . 559

8.24. Nutritional care of the polymorbid patient in medical wards ......... 561
8.24.1. Pathophysiological considerations .. 561

8.24.2. Practical consequences .......... 562

8.25. Nutritional support during pregnancy and breastfeeding...... 565

8.25.1. Pathophysiology . . . . . . . . . . . 565

8.25.2. Indications for and aims of nutritional support................. 566

8.25.3. Parenteral nutrition in pregnancy and lactation.................... 567

\subsection{Nutritional support in} neonatology ................. 569

8.26.1. Enteral or parenteral nutrition? ... . 570 8.26.2. Goals of nutritional support ...... 571

8.26.3. Early nutritional management .... 572

8.26.4. Parenteral nutrition ............ 573

8.26.5. Complications of parenteral nutrition................. 581

8.26.6. Monitoring of Nutritional Status . . . 582 8.26.7. Enteral nutrition .............. 583

8.27. Nutritional support in infants, children, and adolescents. . . . . . . . 587

8.27.1. Diagnostic approach. . . . . . . . . . 587

8.27.2. Nutritional support. . . . . . . . . . . 589

8.27.2.1. Enteral nutrition .............. 590

8.27.2.2. Parenteral nutrition ............ 601

8.28. Nutrition in very old patients .... 611

8.28.1. Determinants of undernutrition in the elderly .............. 612

8.28.1.1. Changes in body composition and function ................6 613

8.28.1.2. Appetite in the elderly . . . . . . . 615 8.28.1.3 Small-bowel bacterial overgrowth . . . 617 8.28.1.4. The ageing immune system ...... 617

8.28.2. Drug interactions in the elderly .... 618

8.28.3. Undernutrition in the elderly and outcomes .................6 618

8.28.4. Detection of undernutrition in the elderly . . . . . . . . . . 619

8.28.5. Changes in nutrient requirements ... 621 8.28.6. Nutritional intervention . . . . . . . 623 8.28.7. Ethical considerations .......... 626

8.29. Home artificial nutrition . . . . . . 628

8.29.1. Home parenteral nutrition (HPN) . . 628

8.29.1.1. Indications for HPN . . . . . . . . . . . 629

8.29.1.2. Methods for HPN application. . . . . . 630

8.29.1.3. Complications of HPN. . . . . . . . . . 631

8.29.2. Home enteral nutrition (HEN) . . . 632

8.29.2.1. Techniques of HEN . . . . . . . . . 632 
8.29.2.2. Complications of HEN.

633

8.29.3. How to begin home artificial nutrition

633

8.30. Nutrition in sports

8.30.1. Energy expenditure during physical activity .................. 636

8.30.1.1. Aerobic and anaerobic energy metabolism 636

8.30.2.2. Anaerobic and aerobic pathways for energy production ............6 637

8.30.1.3. Exercise intensity and substrate utilisation 640

8.30.1.4. Adaptations in metabolic and physiological systems depend on the type of exercise

8.30.2. Relative energy deficiency syndrome

8.30.2.1. Pathogenesis 642

8.30.2.2. Clinical and performance relevance of relative energy deficiency in sports. 642

8.30.2.3. Diagnosis of relative energy deficiency in sports. 642
8.30.2.4. Treatment of relative energy deficiency in sports. . . . . . . . . . 643

8.30.3. Sport-specific nutrition: The endurance athlete 645

8.30.3.1. Recommendation for daily nutrient intake for endurance athletes ..... 645

8.30.3.2. Nutritional preparation of an endurance athlete for competition . . 647

8.30.3.3 Recommendations for food and fluid intake during endurance competitions

8.30.3.4. Nutrition for recovery from competition or exhausting training sessions .................... 648

8.30.4. Sport-specific nutrition: Power and strength sports.............. 648

8.30.4.1. Carbohydrate intake for power and strength sports.............. 649

8.30.4.2. Protein intake for power and strength sports. . . . . . . . . . . . 649

8.30.4.3. Fat intake . . . . . . . . . . . . . 651

8.30.5. Nutritional supplements in sports . . . 651

INDEX 655 